\title{
Health facility readiness and provider knowledge as correlates of adequate diagnosis and management of pre- eclampsia in Kinshasa, Democratic Republic of Congo
}

Dalau Mukadi Nkamba ${ }^{1,2^{*}}$ (D), Roland Vangu ${ }^{3}$, Moyene Elongi ${ }^{3,4}$, Laura A. Magee ${ }^{5}$, Gillbert Wembodinga ${ }^{1}$, Pierre Bernard ${ }^{6}$, John Ditekemena ${ }^{1}$ and Annie Robert ${ }^{2}$

\begin{abstract}
Background: Hypertensive disorders in pregnancy are the second most common cause of maternal mortality in the Democratic Republic of Congo (DRC), accounting for $23 \%$ of maternal deaths. This study aimed to assess facility readiness, and providers' knowledge to prevent, diagnose, and treat pre-eclampsia.

Methods: A facility-based cross-sectional study was conducted in 30 primary health centres (PHCs) and 28 referral facilities (hospitals) randomly selected in Kinshasa, DRC. In each facility, all midwives and physicians involved in maternal care provision $(n=197)$ were included. Data on facility infrastructure and providers' knowledge about preeclampsia were collected using facility checklists and a knowledge questionnaire. Facility readiness score was defined as the sum of 13 health commodities needed to manage pre-eclampsia. A knowledge score was defined as the sum of 24 items about the diagnosis, management, and prevention of pre-eclampsia. The score ranges from 0 to 24, with higher values reflecting a better knowledge. The Mann-Witney $U$ test was used to compare median readiness scores by facility type and ownership; and median knowledge scores between midwives in hospitals and in PHCs, and between physicians in hospitals and in PHCs.

(Continued on next page)
\end{abstract}

\footnotetext{
* Correspondence: dkanba@yahoo.fr

${ }^{1}$ Kinshasa School of Public Health, Faculty of Medicine, University of Kinshasa,

Kinshasa, Democratic Republic of Congo

${ }^{2}$ Pôle d'Épidémiologie et Biostatistique, Université catholique de Louvain

(UCLouvain), Institut de Recherche Expérimentale et Clinique (IREC), Clos

Chapelle-aux-champs, 30 bte B1.30.13, 1200 Brussels, Belgium

Full list of author information is available at the end of the article
}

(c) The Author(s). 2020 Open Access This article is licensed under a Creative Commons Attribution 4.0 International License, which permits use, sharing, adaptation, distribution and reproduction in any medium or format, as long as you give appropriate credit to the original author(s) and the source, provide a link to the Creative Commons licence, and indicate if changes were made. The images or other third party material in this article are included in the article's Creative Commons licence, unless indicated otherwise in a credit line to the material. If material is not included in the article's Creative Commons licence and your intended use is not permitted by statutory regulation or exceeds the permitted use, you will need to obtain permission directly from the copyright holder. To view a copy of this licence, visit http://creativecommons.org/licenses/by/4.0/ The Creative Commons Public Domain Dedication waiver (http://creativecommons.org/publicdomain/zero/1.0/) applies to the data made available in this article, unless otherwise stated in a credit line to the data. 


\begin{abstract}
(Continued from previous page)
Results: Overall, health facilities had 7 of the 13 commodities, yielding a median readiness score of 53.8\%(IQR: 46.2 to $69.2 \%)$. Although all provider groups had significant knowledge gaps about pre-eclampsia, providers in hospitals demonstrated slightly more knowledge than those in PHCs. Midwives in public facilities scored higher than those in private facilities (median(IQR): $8(5$ to 12 ) vs $7(4$ to 8 ), $p=0.03$ ). Of the 197 providers, $91.4 \%$ correctly diagnosed severe pre-eclampsia. However, 43.9 and $82.2 \%$ would administer magnesium sulfate and anti-hypertensive drugs to manage severe pre-eclampsia, respectively. Merely 14.2 and $7.1 \%$ of providers were aware of prophylactic use of aspirin and calcium to prevent pre-eclampsia, respectively.

Conclusion: Our study showed poor availability of supplies to diagnose, prevent and treat pre-eclampsia in Kinshasa. While providers demonstrated good knowledge regarding the diagnosis of pre-eclampsia, they have poor knowledge regarding its prevention and management. The study highlights the need for strengthening knowledge of providers toward the prevention and management of pre-eclampsia, and enhancing the availability of supplies needed to address this disease.
\end{abstract}

Keywords: Pre-eclampsia, Knowledge, Healthcare providers, Facility readiness, Kinshasa

\section{Background}

Hypertensive disorders in pregnancy (HDP), including pre-eclampsia and eclampsia (PE/E), are the second most common cause of maternal mortality worldwide, accounting for $10-15 \%$ of direct maternal deaths $[1,2]$. Globally, it is estimated that 76,000 women and 500,000 newborn die from HDP annually [3]. Most of the deaths (99\%) occur in low- and middle-income countries (LMICs) $[4,5]$. These deaths are preventable by early detection, adequate treatment and timely delivery [6-9]. Effective interventions to address HDP exist, however, their implementation in LMICs remains challenging [10-12]. Systematic reviews and trials have shown the effectiveness of aspirin in the prevention of preeclampsia [10, 13-15], and the effectiveness of magnesium sulfate in the management of severe pre-eclampsia and eclampsia $[11,16,17]$. The World Health Organization (WHO) has considered magnesium sulfate as the first-line drug for eclampsia prevention and treatment for more than a decade [18]. In a review of interventions to decrease HDP-related maternal deaths, it was estimated that a package of interventions including the detection of proteinuria and hypertension in pregnancy, timely treatment of severe pre-eclampsia and eclampsia with magnesium sulfate, and early delivery would reduce HDP mortality by at least $84 \%$ in LMICs [19]. Historical data from Sri Lanka indicated that this LMIC was able to reduce the HDP-related maternal deaths from 50 to 10 deaths per 100, 000 births between 1930 and 1990s [19].

In most LMICs however, a huge number of women continue to suffer from HDP without receiving proven lifesaving interventions [6, 20-23]. Poor knowledge about pre-eclampsia among healthcare providers, in addition to the lack of adequate supplies, are contributing factors to the burden of HDP in LMICs [24-28].
According to the $\mathrm{WHO}$, the maternal mortality ratio in the Democratic Republic of Congo (DRC) is estimated at 473 per 100,000 live births [29]. This is higher than one might expect based on a high rate of skilled attendance at delivery $(80 \%)$, and a high rate of antenatal care attendance (89\%) [30]. In 2018, HDP resulted in 841 (23\%) out of the 3656 maternal deaths reported from the DRC's maternal death surveillance system [31]. Preventing and managing HDP and HDP-related complications could contribute to lower maternal mortality in DRC, and meeting the United Nations Sustainable Development Goal 3 [32].

In a previous study in Kinshasa, Nkamba et al. [33] reported a low proportion of women screened for HDP within antenatal clinics (26.7\%). The authors hypothesized that such low provision of screening for HDP could be a result of a number of factors including knowledge gaps about HDP among healthcare providers. It is essential that providers have the skills and knowledge, supplies and equipment needed to diagnose and promptly address HDP and HDP-related complications in women attending health facilities [33]. At the time of this study, there are no reliable data on the healthcare providers' knowledge about HDP, including preeclampsia in Kinshasa. The purpose of this study was to assess the facility readiness in terms of availability of supplies and equipment to deal with pre-eclampsia; and the providers' knowledge about the prevention, diagnosis, and management of pre-eclampsia.

\section{Methods \\ Study setting}

The study was conducted in Kinshasa, the capital city of the DRC. Kinshasa is divided into 35 health districts, each with an average of 12 health areas and a district hospital. A typical health area provides care for a population of 10,000-15,000 inhabitants, with an average of 6 
primary health centres (PHCs) that provide basic curative and preventive services including routine antenatal care. According to the DRC's health policy, a PHC is staffed by 2 to 4 midwives, and there should not be a physician at this level [34].

A district hospital (or Referral Health Centre where no district hospital exists) is a referral facility for PHCs and provides comprehensive emergency obstetric and neonatal care.

A provincial referral hospital and a teaching hospital that are tertiary-level facilities are also located in Kinshasa. Some PHCs refer directly to these tertiarylevel facilities [34].

In DRC, PHCs are expected to manage mild preeclampsia using antihypertensive drugs. However, in the case of severe pre-eclampsia, PHCs should administer the initial loading dose of magnesium sulfate, then immediately transfer the women to district hospitals. The management of severe pre-eclampsia at the district hospital level includes the provision of antihypertensive drugs, and the Prichard regimen of magnesium sulfate (loading doses of $4 \mathrm{~g}$ IV and $10 \mathrm{~g} \mathrm{IM}$, and maintenance dosing of $5 \mathrm{~g}$ IM every $4 \mathrm{~h}$ ) [35].

\section{Study design, population and sampling}

This was a facility-based cross-sectional study. All of Kinshasa's health facilities that provide emergency obstetric and neonatal care (EmONC) were stratified into (i) primary facilities comprising PHCs; (ii) secondary facilities comprising district hospitals and referral health centres; and (iii) tertiary facilities including the provincial referral hospital and the teaching hospital.

In each stratum, the sample size of health facilities was obtained by using the formula for a proportion within a finite population size [36] of 837 primary, 138 secondary and 2 tertiary facilities according to the data from the Kinshasa Provincial Ministry of Health.

To estimate the sample size of health facilities in each stratum, we considered a prior estimate of $23 \%$ for health facilities that have dipsticks for proteinuria testing in Kinshasa, as per the Services Availability and Readiness Assessment study (SARA) survey in DRC [37]; a margin error of $15 \%$ as per WHO recommendations [36]. We thus determined that 30 primary, 26 secondary and 2 tertiary health facilities were required, leading to a total of 58 facilities.

Both tertiary health facilities were included in the survey. However, the 30 primary and the 26 secondary facilities were selected randomly among the sampling frame of 837 and 138 facilities, respectively.

Within each selected health facility, all midwives and physicians involved in antenatal or maternity care provision, and posted during the day of the survey were included in the study $(n=197)$.

\section{Data collection}

Twelve physicians were recruited as interviewers based on their previous experience in data collection, and two health officers as supervisors. Interviewers and supervisors were trained for five days before data collection. The training focused on the aim of the study, study procedures, and data collection techniques. A checklist for facility inventory was used to capture the availability of key supplies, drugs, and equipment needed to prevent, diagnose, and manage pre-eclampsia based on the DRC's national guidelines. The inventory was completed as the team observed the pharmacy, laboratory, ANC, labor, and delivery areas. Each of the following health commodities was scored 1 point when available in the facility on the day of the survey, and 0 otherwise: Aspirin tablet, calcium gluconate, any fluids (saline, ringer lactate or dextrose), urine test for protein, potocols for management of $\mathrm{PE} / \mathrm{E}$, indwelling urinary catheter, blood pressure machine, stethoscope, fetoscope, oxygen cylinder and adult mask, and ambulance. One point was given for either antihypertensive drug available (nifedipine, hydralazine or methyldopa). Another point was given for either anticonvulsant available (magnesium sulfate or diazepam). We calculated the readiness score as a cumulative number of health commodities available in the health facility on the day of the survey, ranging from 0 to 13 . We reported the score as a percentage of commodities available out of the 13 possible. The score ranged from 0 to $100 \%$, with a high value reflecting better availability. We grouped facilities into three categories according to tertiles of the readiness score: lowtertile if the score ranged from 30.8 to $53.8 \%$, middletertile if the score ranged from 53.9 to $69.2 \%$, and hightertile if the score ranged from 69.3 to $92.3 \%$.

A knowledge questionnaire was used to assess provider knowledge about pre-eclampsia. The knowledge questionnaire was based on the WHO and DRC's guidelines [18, 35], and previous studies which assessed providers' knowledge and clinical judgment regarding the diagnosis and management of pre-eclampsia [23, 38, 39]. The questionnaire consisted of a written case scenario and related "yes/no" items. Each item was scored 1 if the correct answer was given by the healthcare provider, or 0 otherwise. The scenario involved a 20-year-old woman at 37 weeks of pregnancy, complaining of severe headache and blurred vision. Providers learned that the woman had a blood pressure of 160/110 $\mathrm{mmHg}$ and 3+ urine protein. At each step in the scenario, providers were asked how the case should be managed.

Based on DRC's and WHO guidelines [18, 35], we calculated a knowledge score about diagnosis and management of severe pre-eclampsia by summing responses to the 12 following items: measuring blood pressure, monitoring fetal heart, proteinuria testing, naming severe pre- 
eclampsia as diagnosis, administering loading dose of magnesium sulfate, administering maintenance doses of magnesium sulfate, administering anti-hypertensive drugs, referring to a higher-level health facility, indwelling urinary catheter, inducing labor, monitoring magnesium sulfate toxicity, and continuing magnesium sulfate for $24 \mathrm{~h}$ after delivery. The score ranged from 0 to 12 , with a high value reflecting better knowledge.

The questionnaire also included questions to assess providers' knowledge regarding preventative interventions and risk factors for pre-eclampsia. The risk factors included primiparity, obesity, multiple pregnancy, maternal age, pre-eclampsia in a previous pregnancy (if parous), autoimmune disease, family history of preeclampsia, history of diabetes, history of chronic hypertension, and a history of renal disease [40]. The prophylactic interventions of pre-eclampsia included the use of low dose aspirin and calcium. A knowledge score about prevention of pre-eclampsia was built by summing the number of risk factors and prophylactic interventions spontaneously mentioned by the health provider. The score ranges from 0 to 12 , with a high value reflecting better knowledge.

The knowledge score about diagnosis, management, and prevention of pre-eclampsia was obtained by summing the knowledge score about diagnosis and management of severe pre-eclampsia, and the knowledge score about prevention of pre-eclampsia. The score ranges from 0 to 24 , with higher values reflecting a better knowledge.

The questionnaire also included data about providers' characteristics: type (midwives or physicians), training and experience with ANC and pre-eclampsia management; and facilities' characteristics such as ownership (private or public), location (urban or rural), and type (PHCs or hospital).

Prior to the actual data collection, the questionnaire was pilot-tested on 20 healthcare providers in 5 health facilities not participating in this study.

The questionnaire was administrated as face-to-face interviews. The data were collected between October 2017 and January 2018.

\section{Data analysis}

Data were entered into EpiData software version 3.1 and subsequently exported into Stata version 14.1. Secondary and tertiary health facilities were grouped into one category named "hospitals", as they all represent referral units for PHCs. There were no missing data.

We estimated the proportions of facilities having a given supply, drug or equipment by type of facilities (PHCs or hospitals), and by ownership (private or public). For each type of health provider, we estimated the proportion of those who responded correctly to a given knowledge item, by type of health facility. Proportions were compared using Pearson's chi-square test or using Fisher's exact test in cases where expected cell counts were below 5 .

Continuous variables were described as mean and standard deviation $( \pm \mathrm{SD})$ or as median and interquartile range (IQR). The Mann-Whitney $U$ test was used to compare the median readiness scores between hospital and PHCs, and between private and public facilities. The test was also used to compare the median knowledge scores between midwives in hospitals and those in PHCs, between physicians in hospitals and those in PHCs, and between providers in private and in public facilities. A $P$ value less than 0.05 was considered to indicate statistical significance.

\section{Results}

Table 1 shows the characteristics of the antenatal clinics and healthcare providers included in the study, by facility type and ownership. Of the 58 health facilities, 41 (70.7\%) were private and $17(29.3 \%)$ were public. There were $30(51.7 \%)$ primary facilities and $28(48.3 \%)$ hospitals. The median number of first antenatal visits per month in study facilities was 50 (IQR: 37 to 63). There was a median of 8 (IQR: 5 to 16; range: 1 to 73) midwives per facility, and 2(IQR: 1 to 4; range: 0 to 48 ) physicians. There were more physicians in hospitals than in PHCs (median (IQR): 3 (2 to 14) vs 1 (0 to 2 )), and more in public than in private facilities (median (IQR): 6 (3 to $22)$ vs 1 ( 1 to 2$)$ ). Overall $12.1 \%$ of facilities, $(7.3 \%$ of private and $23.4 \%$ of public facilities), received drugs, supplies and equipment to manage pre-eclampsia from government or non-governmental organizations (NGOs).

Of the 197 providers included in the study, 122 (61.9\%) were midwives and 75 (38.1\%) were physicians; $131(66.5 \%)$ were female. In public facilities physicians were the most interviewed (61.8\%), while in private facilities midwives were the most interviewed (74.4\%). In public facilities $23(88.5 \%)$ midwives were included in hospitals, whereas in private facilities $63(65.6 \%)$ midwives were from PHCs (data not shown). A quarter of providers (24.9\%) declared they received in-service training regarding the management of HDP. Half of the providers have been working in maternal health for more than 7 years (median $=7$; IQR: 3 to 12 years; range: 1 to 20 years).

\section{Facility readiness}

Table 2 shows the availability of each individual health commodity, and the readiness score. On the day of the survey, only half of the health facilities had protocols for the management of pre-eclampsia. Magnesium sulfate and calcium gluconate were available in $36.2 \%$ (95\% CI, 
Table 1 Characteristics of the 58 antenatal clinics sampled in Kinshasa, and of the 197 healthcare providers interviewed within these clinics

\begin{tabular}{|c|c|c|c|c|c|}
\hline \multirow[t]{2}{*}{ Characteristics } & \multicolumn{2}{|l|}{ Facility Type } & \multicolumn{2}{|c|}{ Facility ownership } & \multirow{2}{*}{$\begin{array}{l}\text { Total } \\
(n=58)\end{array}$} \\
\hline & Hospitals $(n=28)$ & PHCs $(n=30)$ & Public $(n=17)$ & Private $(n=41)$ & \\
\hline \multicolumn{6}{|l|}{ Health facilities } \\
\hline \multicolumn{6}{|l|}{ Number of ANC pregnant women—no./mth } \\
\hline Median (IQR) & $56(42-95)$ & $42(32-58)$ & $43(36-54)$ & $53(37-78)$ & $50(37-63)$ \\
\hline Range & $29-408$ & $27-449$ & $29-158$ & $27-449$ & $27-449$ \\
\hline \multicolumn{6}{|l|}{ Number of physicians—no. } \\
\hline Median (IQR) & $3(2-14)$ & $1(0-2)$ & $6(3-22)$ & $1(1-2)$ & $2(1-4)$ \\
\hline Range & $1-48$ & $0-6$ & $2-48$ & $0-12$ & $0-48$ \\
\hline \multicolumn{6}{|l|}{ Number of midwives-no. } \\
\hline Median (IQR) & $10(7-23)$ & $7(4-9)$ & $22(10-39)$ & $7(5-9)$ & $8(5-16)$ \\
\hline Range & $1-73$ & $1-26$ & $4-73$ & $1-20$ & $1-73$ \\
\hline Receives supplies from partners-no.(\%) ${ }^{a}$ & $5(17.9)$ & $2(6.7)$ & $4(23.4)$ & $3(7.3)$ & $7(12.1)$ \\
\hline Healthcare providers & $(n=107)$ & $(n=90)$ & $(n=129)$ & $(n=68)$ & $(n=197)$ \\
\hline \multicolumn{6}{|l|}{ Type-no.(\%) } \\
\hline Midwives & $56(52.3)$ & $66(73.3)$ & $26(38.2)$ & $96(74.4)$ & $122(61.9)$ \\
\hline Physicians & $51(47.7)$ & $24(26.7)$ & $42(61.8)$ & 33 (25.6) & $75(38.1)$ \\
\hline \multicolumn{6}{|l|}{ Gender-no.(\%) } \\
\hline Female & $72(67.3)$ & $59(65.6)$ & $88(68.2)$ & $43(63.2)$ & $131(66.5)$ \\
\hline Male & $35(32.7)$ & $31(34.4)$ & $25(36.8)$ & $41(31.8)$ & $66(33.5)$ \\
\hline \multicolumn{6}{|l|}{ Age-yrs } \\
\hline Median (IQR) & $40(33-48)$ & $41(36-47)$ & $39(34-46)$ & $42(35-49)$ & $40(34-48)$ \\
\hline Range & $27-55$ & $30-55$ & $27-55$ & $27-55$ & $27-55$ \\
\hline \multicolumn{6}{|l|}{ Experience within maternal health care-yrs } \\
\hline Median (IQR) & $7(2-12)$ & $7(3-11)$ & $6(2-10)$ & $8(3-13)$ & $7(3-12)$ \\
\hline Range & $1-20$ & $1-19$ & $1-20$ & $1-19$ & $1-20$ \\
\hline In-service training一no.(\%) ${ }^{b}$ & $25(23.4)$ & $24(26.7)$ & $21(30.9)$ & $28(21.7)$ & $49(24.9)$ \\
\hline
\end{tabular}

PHCs Primary health centres, $I Q R$ Interquartile range, Mth Month

ahether facilities received drug, supplies and equipment for diagnosis, prevention and management of pre-eclampsia from the government or non-governmental organizations

${ }^{\mathrm{b}}$ Whether healthcare providers declared they received in-service training regarding the management of hypertensive disorders in pregnancy

24.6-49.6\%) and 31.0\% (95\% CI, 20.2-44.4\%) of facilities, respectively. There was no significant difference in the availability of magnesium sulfate between private and public facilities $(35.3 \%$ vs $36.6 \%, p=0.93)$, neither between hospitals and PHCs $(42.9 \%$ vs $30.0 \%, p=0.31)$. Calcium gluconate was significantly more available in public than in private facilities $(52.9 \%$ vs $21.9 \%, p=$ 0.02). Less than one-third of facilities (29.3\%; $95 \%$ CI: $18.8-42.6 \%)$ had aspirin. The availability of aspirin was significantly higher in public than in private facilities ( $47.1 \%$ vs $21.9 \%, p=0.04)$, however, there was no significant difference between hospitals and PHCs (35.7\% vs $23.3 \%, p=0.3$ ). Anti-hypertensive drugs such as methyldopa, nifedipine and hydralazine were available only in $18.9 \%$ (95\% CI, 10.6-31.5\%), 15.5\% (95\% CI, 8.1-27.6\%) and $6.9 \%$ (95\% CI, 2.5-17.4\%) of health facilities, respectively. There were no significant differences in the availability of anti-hypertensive drugs between public and private facilities, neither between PHCs and hospitals.

Stethoscopes and blood pressure machines were available at all facilities. Slightly more than two-thirds of facilities $(67.2,95 \%$ CI, $55.2-79.3 \%)$ had urine tests for protein. Only $24.1 \%$ of facilities $(53.6 \%$ of hospitals and $20 \%$ of PHCs, $p=<0.01$ ) had an ambulance stationed on their grounds. Overall, health facilities had a median 7 of the 13 health commodities, yielding a median readiness score of $53.8 \%(\mathrm{IQR}: 46.2$ to $69.2 \%)$. The median readiness score in public and private facilities were 69.2 and $53.8 \%$, respectively, with no significant difference. Hospitals scored significantly higher than $\mathrm{PHCs}(69.2 \%$ vs $53.8 \%, p=0.011$ ). Facilities receiving health commodities form government or NGOs scored better than their counterparts, although the difference was not statistically 
Table 2 Availability of supplies, drugs and equipment to prevent and manage pre-eclampsia and eclampsia, according to facility type and ownership

\begin{tabular}{|c|c|c|c|c|c|c|c|}
\hline \multirow[t]{2}{*}{ Variable } & \multicolumn{3}{|c|}{ Facility ownership } & \multicolumn{3}{|l|}{ Facility type } & \multirow{2}{*}{$\begin{array}{l}\text { All }(n= \\
58)\end{array}$} \\
\hline & Public $(n=17)$ & Private $(n=41)$ & $p$-value & Hospitals $(n=28)$ & PHCs $(n=30)$ & $p$-value & \\
\hline \multicolumn{8}{|c|}{ Percent of facilities having the following drugs and supplies_-no. (\%) } \\
\hline Aspirin tablet & $8(47.1)$ & $12(21.9)$ & 0.04 & $10(35.7)$ & $7(23.3)$ & 0.30 & $17(29.3)$ \\
\hline Magnesium sulfate inj & $6(35.3)$ & $15(36.6)$ & 0.93 & $12(42.9)$ & $9(30.0)$ & 0.31 & $21(36.2)$ \\
\hline Diazepam inj & $12(70.6)$ & $23(56.1)$ & 0.30 & $19(67.9)$ & $16(53.3)$ & 0.26 & $35(60.3)$ \\
\hline Hydralazine inj & $1(5.9)$ & $3(7.3)$ & 0.67 & $3(10.7)$ & $1(3.3)$ & 0.28 & $4(6.9)$ \\
\hline Nifedipine tablet & $4(23.5)$ & $5(12.2)$ & 0.43 & $5(17.9)$ & $4(13.3)$ & 0.45 & $9(15.5)$ \\
\hline Methyldopa tablet & $5(29.4)$ & $6(14.6)$ & 0.17 & $8(28.6)$ & $3(10.0)$ & 0.07 & $11(18.9)$ \\
\hline Calcium gluconate inj & $9(52.9)$ & $9(21.9)$ & 0.02 & $10(35.7)$ & $8(26.7)$ & 0.46 & $18(31.0)$ \\
\hline Any fluids (saline, ringer lactate, dextrose) inj & $17(100)$ & $38(92.7)$ & 0.35 & $28(100.0)$ & $27(90.0)$ & 0.24 & $55(94.8)$ \\
\hline Urine test for protein ${ }^{\mathrm{a}}$ & $9(52.9)$ & $30(73.2)$ & 0.14 & $22(78.5)$ & $17(56.7)$ & 0.17 & $39(67.2)$ \\
\hline Potocols for management of PE/E & $9(52.9)$ & $20(48.8)$ & 0.77 & $18(64.3)$ & $11(36.7)$ & 0.04 & $29(50.0)$ \\
\hline Indwelling urinary catheter & $9(52.9)$ & $23(56.1)$ & 0.83 & $15(53.6)$ & $17(56.7)$ & 0.81 & $32(55.2)$ \\
\hline \multicolumn{8}{|c|}{ Percent of facilities having the following equipment-no. (\%) } \\
\hline Blood pressure machine & $17(100)$ & $41(100)$ & $>0.99$ & $28(100)$ & $30(100)$ & $>0.99$ & $58(100)$ \\
\hline Stethoscope & $17(100)$ & $39(100)$ & $>0.99$ & $28(100)$ & $30(100)$ & $>0.99$ & $58(100)$ \\
\hline Fetoscope & $17(100)$ & $39(100)$ & $>0.99$ & $28(100)$ & $30(100)$ & $>0.99$ & $58(100)$ \\
\hline Oxygen cylinder and adult mask & $5(29.4)$ & $2(4.9)$ & 0.01 & $5(17.9)$ & $2(6.7)$ & 0.18 & $7(12.1)$ \\
\hline Ambulances & $10(58.8)$ & $11(26.8)$ & 0.02 & $15(53.6)$ & $6(20.0)$ & $<0.01$ & $14(24.1)$ \\
\hline \multicolumn{8}{|l|}{ Readiness score-\% } \\
\hline Median & 69.2 & 53.8 & 0.14 & 69.2 & 53.8 & 0.011 & 53.8 \\
\hline Interquartile range & 53.8 to 84.6 & 46.1 to 69.2 & & 53.8 to 76.9 & 38.4 to 69.2 & & 46.2 to 69.2 \\
\hline Tertile of readiness score-no.(\%) & & & 0.26 & & & 0.04 & \\
\hline Low tertile & $6(35.3)$ & $24(58.5)$ & & $10(35.7)$ & $20(66.7)$ & & $30(51.7)$ \\
\hline Middle tertile & $6(35.3)$ & $10(24.4)$ & & $9(32.1)$ & $7(23.3)$ & & $16(27.6)$ \\
\hline High tertile & $5(29.4)$ & $7(17.1)$ & & $9(32.1)$ & $3(10.0)$ & & $12(20.7)$ \\
\hline
\end{tabular}

PHCs Primary health centres, inj Injectable, PE/E Pre-eclampsia and eclampsia

${ }^{a}$ Dipsticks or acetic acid

significant (median (IQR): $61.5 \%$ (48.2 to $69.2 \%$ ) vs $53.8 \%(46.2$ to $62.9 \%), p=0.55$ ) (data not shown). Almost $59 \%$ of private facilities and $35 \%$ of public facilities fell into the low tertile of readiness.

\section{Providers' knowledge}

Table 3 shows provider knowledge regarding the diagnosis and management of severe pre-eclampsia. Overall, severe pre-eclampsia was correctly diagnosed by $91.4 \%$ (95\% CI, 86.5-94.6\%) of providers. Among providers who correctly diagnosed severe pre-eclampsia, however, only $43.9 \%$ (95\% CI, 36.5-51.5\%) would administer a loading dose of magnesium sulfate. More physicians in hospitals than in PHCs would administer a loading dose of magnesium sulfate to manage severe pre-eclampsia $(58.8 \%$ vs $33.3 \%, p=0.04)$. Only $10.3 \%$ (95\% CI, $6.3-16.5 \%$ ) of providers would monitor the magnesium sulfate toxicity.

The median knowledge score about diagnosis and management of severe pre-eclampsia was 5 (IQR, 4 to
7). Midwives in hospitals scored better than those in PHCs (median (IQR): 5.5 (4 to 7 ) vs 5 ( 4 to 6 ), $p=<$ 0.01 ). Physicians in hospitals scored better than those in PHCs (median (IQR): 6 ( 5 to 8 ) vs 5 ( 4 to 7 ), $p=0.03$ ).

Table 4 shows provider knowledge of risk factors and prevention strategies of pre-eclampsia.

Overall, $44.2 \%$ of providers mentioned chronic hypertension as a risk factor for pre-eclampsia. Low-dose aspirin and calcium were cited as prophylactic drugs of pre-eclampsia by only $14.2 \%$ (95\% CI, 9.7-19.9\%) and $7.1 \%$ (95\% CI, 3.9-11.6\%) of providers, respectively. Almost two-thirds of providers $(62.4 \%$; $95 \%$ CI, $55.3-$ 69.2\%) mentioned the low-salt diet as a prophylaxis for pre-eclampsia. The median knowledge score about the prevention of pre-eclampsia was 2 (IQR, 1 to 4). Midwives in hospitals were more knowledgeable than in PHCs (median (IQR): 2 ( 1 to 4 ) vs 1 (0 to 2 ), $p=0.01$ ).

Figures 1 and 2 present the combined knowledge score by facility type and ownership, respectively. The 
Table 3 Proportion of providers responding correctly to case scenario related to diagnosis and management of severe preeclampsia, by provider type, facility type and ownership

\begin{tabular}{|c|c|c|c|c|c|c|c|}
\hline \multirow[t]{2}{*}{ Correct responses to case scenario } & \multicolumn{3}{|l|}{ Midwives } & \multicolumn{3}{|l|}{ Physicians } & \multirow{2}{*}{$\begin{array}{l}\text { All }(n= \\
197)\end{array}$} \\
\hline & PHCs $(n=66)$ & Hospitals $(n=56)$ & $p$-value & PHCs $(n=24)$ & Hospitals $(n=51)$ & $p$-value & \\
\hline \multicolumn{8}{|l|}{ Initial assessment } \\
\hline Check blood pressure & 87.9 & 94.6 & $0.22^{*}$ & 83.3 & 98.4 & 0.03 & 91.9 \\
\hline Monitor fetal heart rate & 100 & 100 & $>0.99$ & 100 & 100 & $>0.99$ & 100 \\
\hline Assess urine for protein & 42.4 & 46.4 & 0.66 & 54.2 & 39.2 & 0.22 & 44.2 \\
\hline \multicolumn{8}{|l|}{ Diagnosis and management of severe pre-eclampsia } \\
\hline Diagnose severe pre-eclampsia & 81.8 & 91.1 & 0.14 & 100 & 100 & 0.99 & 91.4 \\
\hline Administer loading dose of $\mathrm{MgSO}_{4}{ }^{\mathrm{a}}$ & 31.5 & 47.1 & 0.11 & 33.3 & 58.8 & 0.04 & 43.9 \\
\hline Immediately refer to higher facility ${ }^{a}$ & 38.9 & 19.6 & 0.03 & 8.3 & 3.9 & $0.33^{*}$ & 19.4 \\
\hline Administer maintenance doses of $\mathrm{MgSO}_{4}{ }^{\mathrm{ab}}$ & 33.3 & 48.8 & 0.18 & 31.8 & 57.1 & 0.48 & 45.5 \\
\hline Administer anti-hypertensive drugs ${ }^{a}$ & 68.5 & 84.3 & 0.06 & 83.3 & 94.1 & $0.14^{*}$ & 82.2 \\
\hline Induce labor ${ }^{b}$ & 3.3 & 9.8 & $0.37^{*}$ & 18.2 & 40.8 & 0.06 & 20 \\
\hline Monitor $\mathrm{MgSO}_{4}$ toxicity & 0 & 9.8 & $0.08^{*}$ & 9.1 & 18.4 & $0.27^{*}$ & 10.3 \\
\hline Continue $\mathrm{MgSO}_{4}$ for $24 \mathrm{~h}$ postpartum ${ }^{\mathrm{b}}$ & 6.1 & 7.3 & $0.61^{*}$ & 22.7 & 34.7 & 0.41 & 22.9 \\
\hline \multicolumn{8}{|c|}{ Knowledge score about diagnosis and management of severe pre-eclampsia } \\
\hline Median (IQR) & 5 (4 to 6$)$ & 5.5 (4 to 7 ) & $<0.01$ & $5(4$ to 7$)$ & $6(5$ to 8$)$ & 0.03 & 5 (4 to 7 ) \\
\hline
\end{tabular}

PHCs Primary health centres, IQR Interquartile range, $\mathrm{MgSO}_{4}$ Magnesium sulfate

*Fisher exact test

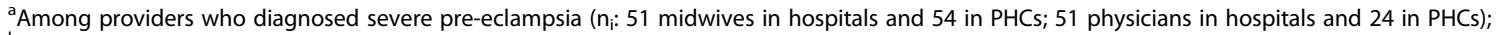

${ }^{\mathrm{b}}$ Among providers who did not refer to a higher level facility ( $\mathrm{n}_{\mathrm{i}}: 41$ midwives in hospitals and 33 in PHCs; 49 physicians in hospitals and 22 in PHCs)

Table 4 Providers' knowledge toward risk factors and preventive interventions of pre-eclampsia, by provider type, facility type and ownership

\begin{tabular}{|c|c|c|c|c|c|c|c|}
\hline \multirow{2}{*}{$\begin{array}{l}\text { Percentage of providers who } \\
\text { mentioned the following: }\end{array}$} & \multicolumn{3}{|l|}{ Midwives } & \multicolumn{3}{|l|}{ Physicians } & \multirow{2}{*}{$\begin{array}{l}\text { All }(n= \\
197)\end{array}$} \\
\hline & PHCs $(n=66)$ & Hospitals $(n=56)$ & $p$-value & PHCs $(n=24)$ & Hospitals $(n=51)$ & $p$-value & \\
\hline \multicolumn{8}{|l|}{ Risk factors for pre-eclampsia } \\
\hline Chronic hypertension & 36.4 & 35.7 & 0.94 & 41.7 & 64.7 & 0.06 & 44.2 \\
\hline Primiparity & 18.2 & 41.1 & $<0.01$ & 45.8 & 70.6 & 0.04 & 41.6 \\
\hline Pre-eclampsia in previous pregnancy & 15.2 & 32.1 & 0.03 & 54.2 & 49.0 & 0.68 & 33.5 \\
\hline Family history of pre-eclampsia & 12.1 & 30.4 & 0.02 & 29.2 & 54.9 & 0.04 & 30.5 \\
\hline Diabetes mellitus & 16.7 & 26.8 & 0.17 & 29.1 & 41.2 & 0.32 & 27.4 \\
\hline Obesity or overweight & 27.3 & 23.2 & 0.61 & 20.8 & 31.4 & 0.34 & 26.4 \\
\hline Multiple pregnancy & 9.1 & 26.8 & 0.01 & 33.3 & 41.7 & 0.48 & 24.3 \\
\hline Maternal age & 12.1 & 21.4 & 0.17 & 29.2 & 29.4 & 0.98 & 21.3 \\
\hline Chronic renal disease & 4.6 & 5.4 & $0.58^{*}$ & 12.5 & 19.6 & $0.34^{*}$ & 9.6 \\
\hline Autoimmune disease & 0 & 1.8 & $0.46^{*}$ & 0 & 5.9 & $0.31^{*}$ & 2.3 \\
\hline \multicolumn{8}{|l|}{ Preventive intervention of pre-eclampsia } \\
\hline Low-salt diet & 71.2 & 67.9 & 0.69 & 58.3 & 47.1 & 0.36 & 62.4 \\
\hline Physical activity & 24.2 & 21.4 & 0.71 & 25.0 & 5.9 & $0.03^{*}$ & 18.8 \\
\hline Low-dose aspirin & 3.0 & 8.9 & $0.16^{*}$ & 20.8 & 31.4 & 0.34 & 14.2 \\
\hline Calcium & 3.1 & 3.6 & 0.87 & 8.3 & 15.7 & 0.38 & 7.1 \\
\hline \multicolumn{8}{|c|}{ Knowledge score about prevention of pre-eclampsia } \\
\hline Median (IQR) & 1 (0 to 2$)$ & 2 (1 to 4$)$ & 0.01 & 3 (2 to 5$)$ & 4 (2 to 6) & 0.16 & 2 (1 to 4$)$ \\
\hline
\end{tabular}

PHCs Primary health centres

*Fisher exact test 
knowledge score about diagnosis, management, and prevention of pre-eclampsia was higher among midwives in hospitals than in PHCs (median (IQR): 8 (6 to 10) vs 6 (4 to 8 ), $p<0.01$ ), and higher among physicians in hospitals than in PHCs (median (IQR): 10 (8 to 13 ) vs 8 (7 to 11 ), $p=0.04$ ) (Fig. 1). Midwives in public facilities were significantly more knowledgeable than in private facilities (median (IQR): 8 ( 5 to 12 ) vs 7 ( 4 to 8 ), $p=0.03$ ). There was no significant difference between physicians in public and in private facilities (Fig. 2).

\section{Discussion}

We undertook a cross-sectional study to assess readiness to diagnose, prevent and treat pre-eclampsia in health facilities in Kinshasa. This included an evaluation of critical resources for diagnosis, prevention and treatment, and provider knowledge about pre-eclampsia. Our findings showed gaps in the availability of supplies and equipment required to prevent and treat pre-eclampsia, as well as poor knowledge among healthcare providers.

Our study reveals poor availability of health commodities to manage pre-eclampsia in Kinshasa, as half of facilities had a readiness score lower than 53.8\%. No facility had all the nominated commodities at the time of the study. This poor availability may be due to inconsistent supply chain, as only $12.1 \%$ of facilities, mainly hospitals (17.9\%) and public facilities (23.4\%), received these commodities from government or NGOs. As a result, health facilities usually ask patients or their relatives to purchase drugs from outside pharmacies [41]. As such, there may be a lag of time till the drug is made available, depending on affordability and proximity to the pharmacies. This delay may worsen the pregnancy outcome, and it contributes to HDP-related mortality $[28,42,43]$. The tendency to ask patients or their relatives to buy drugs from outside the health facilities has been also reported in other sub-Saharan African countries $[28,44]$.

The higher availability of health commodities in hospitals than in PHCs in Kinshasa was expected, as referral of pre-eclamptic patients to a hospital is a recommended national strategy in DRC [35]. Furthermore, the DRC's guidelines are conflicting, with the national list of essential medicines restricting magnesium sulfate availability only in hospitals, while the EmONC guidelines recommend its availability in both PHCs and hospitals $[45,46]$. Such conflicting recommendations are likely to result in poor availability of drugs in PHCs and need to be addressed.

Previous studies in Africa have reported various patterns of the available maternal health commodities. Some of these studies have favored the availability of

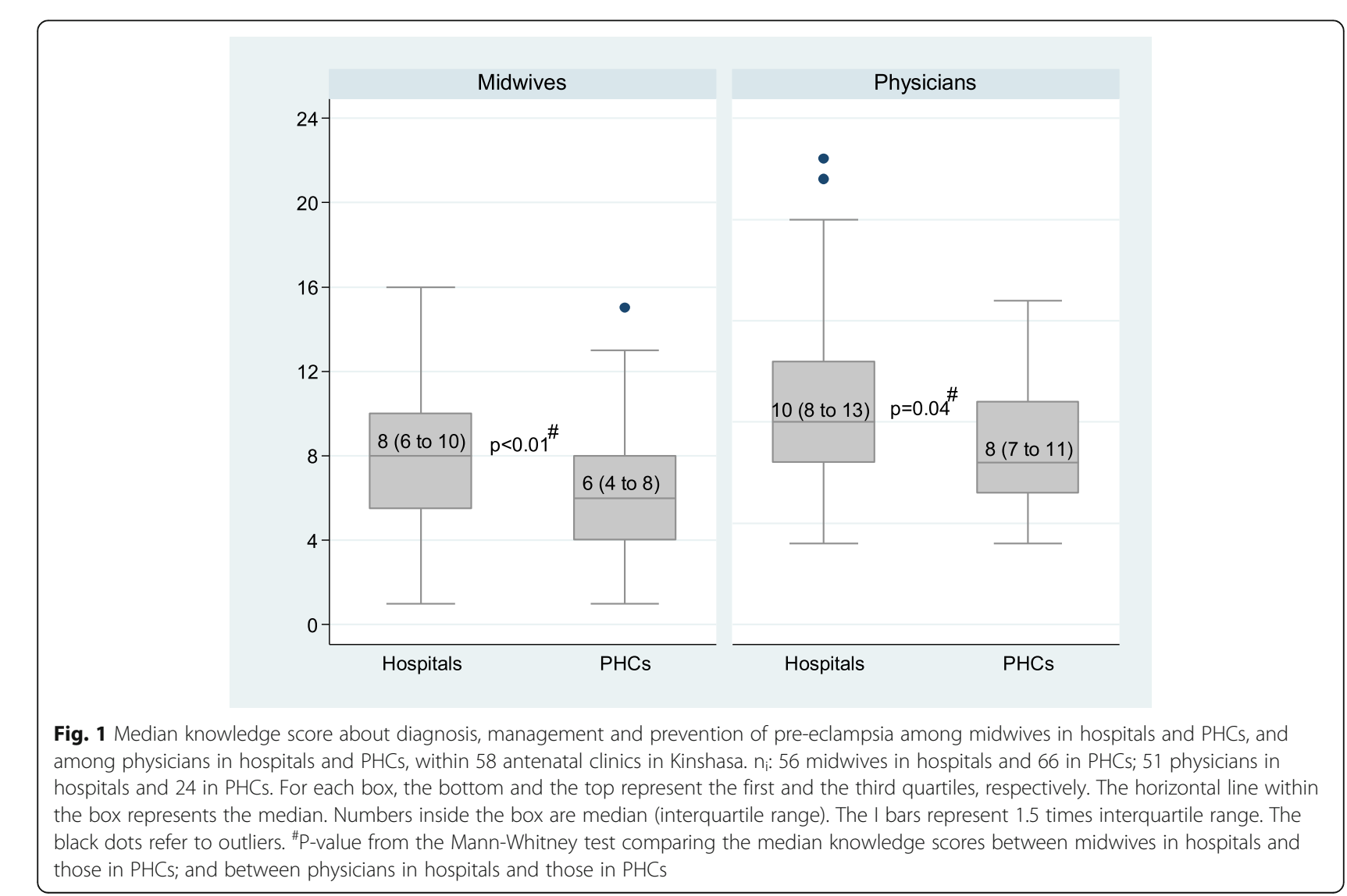




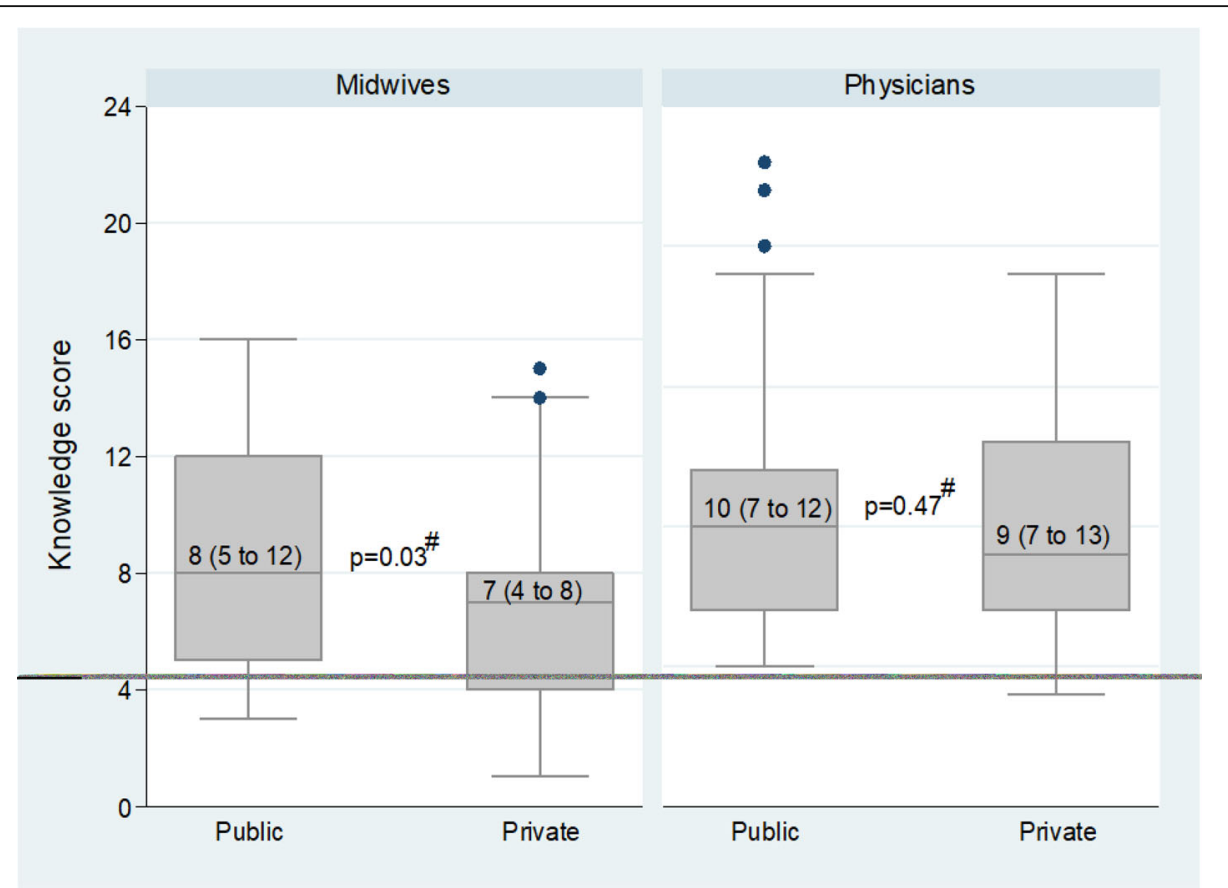

Fig. 2 Median knowledge score about diagnosis, management and prevention of pre-eclampsia among midwives in public and private facilities, and among physicians in in public and private facilities, within 58 antenatal clinics in Kinshasa. $\mathrm{n}_{\mathrm{i}}$ : 26 midwives in public and 96 in private facilities; 42 physicians in apublic and 33 in private facilities. For each box, the bottom and the top represent the first and the third quartiles, respectively. The horizontal line within the box represents the median. Numbers inside the box are median (interquartile range). The I bars represent 1.5 times interquartile range. The black dots refer to outliers. "P-value from the Mann-Whitney test comparing the median knowledge score between midwives in public and those in private facilities; and between physicians in public and those in private facilities

supplies in public facilities, whereas others reported a higher availability in private facilities [47-50]. For instance, a study in Kenya, Uganda and Zambia reported a higher availability of magnesium sulfate and of calcium gluconate in public than in private facilities [48].

In our study public facilities showed better availability of commodities than private facilities, and facilities receiving health commodities from government or NGOs showed better availability than their counterparts, although differences were not statistically significant. This lack of difference in the availability of commodities should be interpreted cautiously as the study was not originally powered to capture such differences.

Despite being on the Congolese essential medicines list [46], aspirin, magnesium sulfate, calcium gluconate, and antihypertensive agents such as nifedipine, methyldopa, and hydralazine, were scarcely available in health facilities in Kinshasa. The availability of drugs such as magnesium sulfate in Kinshasa was similar to that quoted in Nigeria (34\%) [44] but lower than those reported in other LMIC settings $[39,51,52]$.

The availability of proteinuria testing in Kinshasa improved from $23 \%$ in 2014 to $67.2 \%$ in 2018 . However, in a previous study, Nkamba et al. reported that only $26.9 \%$ of pregnant women were screened for proteinuria during a first antenatal visit [33].

The shortage of antihypertensive drugs and magnesium sulfate in health facilities, especially in PHCs, is concerning. In the DRC's health system, PHCs serve as the first point of care facilities. They are expected to initiate antihypertensive and anticonvulsant treatment as early as possible after a diagnosis of severe preeclampsia, before the transfer of women to referral facilities [35]. Anti-hypertensive drugs and magnesium sulfate should be widely available at this level, so that women suffering from pre-eclampsia can be stabilized and referred safely. At both PHCs and hospital level, supplies should be available to avoid delay in treatment.

Our findings also indicate that PHCs face challenges in referring pre-eclamptic women to hospitals, as only a fifth have ambulance. It is unclear in the national guidelines if PHCs should have or should request an ambulance from hospitals when needed [34], yet the availability of ambulance at the hospital level is low. The lack of ambulance in PHCs may result in delay in women with severe preeclampsia being transported to referral facilities, and contribute to the HDP-related mortality.

Only one facility in two had protocols for diagnosis and management of HDP, including the administration of magnesium sulfate and anti-hypertensive drugs. Our 
findings are in line with those reported in other LIMCs, suggesting that the lack of protocols for the management of HDP is a common issue in these settings $[6,44,53]$.

However, none of the protocols in Kinshasa included the identification of women at risk of developing preeclampsia during antenatal care, nor the prophylactic use of low-dose aspirin in such women.

According to the DRC's health policy, the presence of a physician in PHCs is not mandatory [34]. Our study indicates that half of PHCs in Kinshasa, mainly private, have more than one physician. The presence of physicians in PHCs reflects the poor regulation of the DRC's health system as reported by previous studies [54].

The proportion of providers who correctly diagnosed severe pre-eclampsia in our study is higher than that reported in India (78.5\%) [38]. Although 91.4\% of providers correctly diagnosed severe pre-eclampsia based on the case scenario, less than half of them identified treatment with magnesium sulfate as an essential action. The study outlined the discrepancy between the diagnosis and the management of severe pre-eclampsia, suggesting that a substantial number of women with this obstetrical complication may not receive magnesium sulfate, the drug of choice to prevent eclampsia in pre-eclamptic women, nor antihypertensive agents even when they reach health facilities in a timely manner. Our findings are consistent with studies from other settings such as India, Afghanistan, Nigeria that also reported the knowledge gaps between diagnosis and management of severe pre-eclampsia among healthcare providers [38, 39, 44, 55].

When magnesium sulfate is administered, providers should monitor women for warning signs of its toxicity, which may present as loss of tendon reflex, decreased urine output, or depressed respiratory rate $[18,40]$. Our findings suggest that magnesium sulfate is not used adequately in Kinshasa, as only $10 \%$ of providers across all facilities would monitor its toxicity, and only $23 \%$ would continue its administration up to $24 \mathrm{~h}^{\prime}$ post-partum as per WHO and DRC's national guidelines [18, 35].

It is known from the literature that early delivery in severe pre-eclamptic women can contribute to improving pregnancy outcomes $[8,19]$. While the DRC's national guidelines recommend inducing labor at 37 weeks gestation in case of severe pre-eclampsia, the majority of providers in Kinshasa did not identify inducing labor as a critical step in managing severe pre-eclampsia.

Although all provider groups had significant knowledge gaps about pre-eclampsia, providers in hospitals demonstrated slightly more knowledge compared to those in PHCs. This finding is not surprising given that physicians are more plentiful in hospitals than in PHCs and they tend to be more knowledgeable than midwives. National EmONC guidelines are more available in hospitals than in PHCs. Moreover, referral of pre-eclamptic patients to a hospital is a recommended national strategy in DRC. Providers in hospital may have more exposure to patients with pre-eclampsia, and thus more experience than those in PHCs.

A study from Nigeria also identified knowledge gaps about pre-eclampsia across providers both in PHCs and in hospitals [44].

Midwives in public facilities were more knowledgeable than those in private facilities. One possible explanation is that in public facilities $88.5 \%$ of midwives included in the study were from hospitals, whereas in private facilities midwives were mostly from PHCs. In addition, more providers in public facilities than in private facilities received in-service training regarding the management of HDP. There was no significant difference in knowledge between physicians in public and in private facilities. This lack of difference between physicians in public and those in private facilities may result from public-on-private dual practice among physicians, a common practice in Kinshasa, whereby some physicians from public sector are also involved in private facilities to supplement low government salary rates.

In LMICs where biomarkers to identify women at risk of developing pre-eclampsia are not available, scientific bodies recommend relying upon maternal historical and clinical characteristics [40]. The International Federation of Gynecology and Obstetrics (FIGO) has recommended a combination of i) maternal risk factors with ii) mean arterial pressure where it is not possible to measure placental growth factor (PLGF) and uterine artery pulsatility index (UTPI) [56]. In DRC however, there is a lack of consistent national guidelines regarding the prevention of pre-eclampsia, including the identification of women at risk of developing the disease, and the prophylactic use of low-dose aspirin [45]. As a result, slightly more than half (56\%) of providers in our study were not aware of maternal risk factors for pre-eclampsia. Only 14.2 and $7.1 \%$ of providers named low-dose aspirin and calcium as prophylactic drugs for pre-eclampsia, respectively. Our findings regarding the prophylactic use of aspirin are similar to those reported in Nigeria (14\%) but higher than those reported in Bangladesh (2\%). Expectedly, the majority of providers $(62.4 \%)$ mentioned the low-salt diet as a preventative strategy of pre-eclampsia. This is probably because salt restriction is a valid recommendation for hypertensive patients in general. However, scientific bodies including the WHO do not recommend salt restriction during pregnancy to prevent pre-eclampsia $[57,58]$.

Our findings suggest that even when women attend antenatal clinics, they may not be identified as at risk of developing pre-eclampsia. Also, even if identified as being at risk, they may not receive a preventative 
intervention such as low-dose aspirin, resulting in missed opportunities to prevent pre-eclampsia.

In a city such as Kinshasa, most women may choose or are forced to attend private facilities as the latter represent more than $60 \%$ of all facilities [49]. Given the knowledge gaps and shortages of supplies in both public and private facilities, it is not surprising that preeclampsia-related morbidity and mortality are a significant public health problem in Kinshasa. Our study highlighted the need for strengthening providers' knowledge about pre-eclampsia, with a particular emphasis on its prevention and management. The study also highlighted the need for addressing contradictions in the DRC's national guidelines regarding the place of availability of essential drugs and enhancing the availability of supplies and their utilization. In a recently published cluster randomized controlled trial in Kinshasa and Lusaka (Zambia), Althabe et al. showed that a combination of provision of supplies with a behavioral intervention including supportive supervision, the use of opinion leaders, reminders, audit, and feedback, improved the diagnosis and management of maternal conditions such as syphilis [59]. A similar approach could be implemented to improve the quality of care for pre-eclampsia in Kinshasa. Providers' knowledge should be improved by means of evidence-based capacity-building strategies such as simulation-based training that have been proven to be effective in other LMICs $[60,61]$.

Our study has some limitations. We used a case scenario to assess providers' knowledge to prevent and manage pre-eclampsia. Direct observation of clinical practices and case sheet audits would provide a more accurate assessment of provider knowledge. However, this strategy was not feasible in the context of DRC, where clinical records are generally of poor quality [62], and facilities, particularly PHCs do not experience a high volume of cases.

Despite these limitations, this is to our knowledge, the first study that assesses providers' knowledge regarding the prevention and management of pre-eclampsia within a large and representative sample in Kinshasa. While this study was conducted only in Kinshasa, we feel it may also reflect the reality of health facilities in other provinces of the DRC. We encourage similar studies in other provinces of DRC for confirmation. The results of our study may be used to build strategies to improve the quality of care for pre-eclamspia in Kinshasa.

\section{Conclusion}

Our study showed poor availability of supplies and equipment to diagnose, prevent and treat pre-eclampsia within health facilities in Kinshasa. While healthcare providers demonstrated good knowledge regarding the diagnosis of pre-eclampsia, they have poor knowledge regarding its prevention and management. The study highlighted the need for strengthening knowledge of providers toward the prevention and management of pre-eclampsia, and enhancing the availability of equipment, and supplies needed to diagnose and address this life-threatening condition.

\section{Abbreviations \\ ANC: Antenatal care; Cl: Confidence interval; DHS: Demographic and Health Survey; DRC: Democratic Republic of Congo; EmONC: Emergency obstetric and neonatal care; HDP: Hypertensive disorder in pregnancy; IQR: Interquartile range; LMIC: Low- and Middle-Income Country; $\mathrm{MgSO}_{4}$ : Magnesium sulfate; NHIS: National Health Information System; NICE: National Institute for Health and Clinical Excellence; PHCs: Primary health centres; SARA: Service Availability and Readiness Assessment study; SD: Standard deviation}

\section{Acknowledgments}

We are thankful to the United States Agency for International Development (USAID) for funding the thesis of Nkamba Mukadi, Dalau. This work is a preliminary report of data collected for his thesis. This funding source is noncommercial.

We thank Professors Carl Bose for his useful inputs on the manuscript.

\section{Authors' contributions}

DNM, JD and AR designed the research; DNM conducted the fieldwork, analyzed data, and drafted the manuscript. RV, EM, LAM, GW, PB, JD, and AR critically revised the drafted manuscript. All authors read and approved the final manuscript.

\section{Funding}

This study was carried out with funding provided by the United States Agency for International Development (USAID). USAID did not have any role in study design, data collection, and analysis, manuscript development or decision to publish.

\section{Availability of data and materials}

The datasets used during the current study are available from the corresponding author on reasonable request.

Ethics approval and consent to participate

The study protocol was approved by the institutional review board of the Kinshasa School of Public Health ( $n^{\circ}$ ESP/CE/035/2017), the Provincial Ministry of Health, the health district officers, and health facilities' authorities. Participants were informed using the informed consent statement, detailing all relevant aspects of the study. All study participants provided signed written informed consent.

\section{Consent for publication}

Not applicable.

\section{Competing interests}

The authors declare that they have no competing interests.

\section{Author details}

${ }^{1}$ Kinshasa School of Public Health, Faculty of Medicine, University of Kinshasa, Kinshasa, Democratic Republic of Congo. ${ }^{2}$ Pôle d'Épidémiologie et Biostatistique, Université catholique de Louvain (UCLouvain), Institut de Recherche Expérimentale et Clinique (IREC), Clos Chapelle-aux-champs, 30 bte B1.30.13, 1200 Brussels, Belgium. ${ }^{3}$ Department of Gynecology and Obstetrics, University Clinics of Kinshasa, Kinshasa, Democratic Republic of Congo. ${ }^{4}$ Department of Gynecology and Obstetrics, Provincial General Hospital of Kinshasa, Kinshasa, Democratic Republic of Congo. ${ }^{5}$ Department of Women and Children's Health, School of Life Course Sciences, King's College London, London, UK. ${ }^{6}$ Pôle de Gynécologie et Obstétrique, Université Catholique de Louvain (UCLouvain), Institut de Recherche Expérimentale et Clinique (IREC), Brussels, Belgium. 
Received: 23 March 2020 Accepted: 1 October 2020

Published online: 07 October 2020

\section{References}

1. Kinney MV, Kerber KJ, Black RE, Cohen B, Nkrumah F, Coovadia H, et al. SubSaharan Africa's Mothers, newborns, and children: where and why do they die? PLoS Med. 2010;7(6):e1000294 https://www.ncbi.nlm.nih.gov/pmc/ articles/PMC2888581/. Accessed 20 Dec 2019.

2. Say L, Chou D, Gemmill A, Tunçalp Ö, Moller A-B, Daniels J, et al. Global causes of maternal death: a WHO systematic analysis. Lancet Glob Health. 2014;2(6):e323-33 https://www.thelancet.com/pdfs/journals/langlo/ PIIS2214-109X(14)70227-X.pdf. Accessed 20 Dec 2019.

3. Salam RA, Das JK, Ali A, Bhaumik S, Lassi ZS. Diagnosis and management of preeclampsia in community settings in low and middle-income countries. J Fam Med Prim Care. 2015;4(4):501-6 http://www.ncbi.nlm.nih.gov/pmc/ articles/PMC4776599/ Accessed 20 Dec 2019.

4. Moodley J. Maternal deaths due to hypertensive disorders in pregnancy. Best Pract Res Clin Obstet Gynaecol. 2008;22(3):559-67.

5. Ghulmiyyah L, Sibai B. Maternal mortality from preeclampsia/eclampsia. Semin Perinatol. 2012;36(1):56-9.

6. Firoz T, Sanghvi H, Merialdi M, von Dadelszen P. Pre-eclampsia in low and middle income countries. Best Pract Res Clin Obstet Gynaecol. 2011;25(4): 537-48.

7. Goldenberg RL, Jones B, Griffin JB, Rouse DJ, Kamath-Rayne BD, Trivedi N, et al. Reducing maternal mortality from preeclampsia and eclampsia in lowresource countries--what should work? Acta Obstet Gynecol Scand. 2015; 94(2):148-55 https://obgyn.onlinelibrary.wiley.com/doi/full/10.1111/ aogs.12533. Accessed 20 Dec 2019.

8. Goldenberg RL, McClure EM, Macguire ER, Kamath BD, Jobe AH. Lessons for low-income regions following the reduction in hypertension-related maternal mortality in high-income countries. Int J Gynaecol Obstet Off Organ Int Fed Gynaecol Obstet. 2011;113(2):91-5.

9. Moodley J. Maternal deaths associated with hypertension in South Africa: lessons to learn from the Saving Mothers report, 2005-2007. Cardiovasc J Afr. 2011;22(1):31-5 https://www.ncbi.nlm.nih.gov/pmc/articles/PMC373473 8/. Accessed 20 Dec 2019.

10. Rolnik DL, Wright D, Poon LC, O'Gorman N, Syngelaki A, de Paco Matallana $C$, et al. Aspirin versus placebo in pregnancies at high risk for preterm preeclampsia. N Engl J Med. 2017;377(7):613-22 https://www.nejm.org/doi/ full/10.1056/NEJMoa1704559. Accessed 20 Dec 2019

11. Altman D, Carroli G, Duley L, Farrell B, Moodley J, Neilson J, et al. Do women with pre-eclampsia, and their babies, benefit from magnesium sulphate? The Magpie Trial: a randomised placebo-controlled trial. Lancet Lond Engl. 2002;359(9321):1877-90 https://www.thelancet.com/journals/ lancet/article/PIIS0140-6736(02)08778-0/fulltext Accessed 20 Dec 2019.

12. Moore GS, Allshouse AA, Post AL, Galan HL, Heyborne KD. Early initiation of low-dose aspirin for reduction in preeclampsia risk in high-risk women: a secondary analysis of the MFMU High-Risk Aspirin Study. J Perinatol. 2015; 35(5):328-31 https://www.ncbi.nlm.nih.gov/pmc/articles/PMC4838902/. Accessed 20 Dec 2019

13. Greene MF, Solomon CG. Aspirin to prevent preeclampsia. N Engl J Med 2017;377(7):690-1 https://www.nejm.org/doi/full/10.1056/NEJMe1708920. Accessed 20 Dec 2019

14. Wright D, Rolnik DL, Syngelaki A, de Paco Matallana C, Machuca M, de Alvarado $\mathrm{M}$, et al. Aspirin for evidence-based preeclampsia prevention trial: effect of aspirin on length of stay in the neonatal intensive care unit. Am J Obstet Gynecol. 2018;218(6):612.e1-6 https://www.ajog.org/article/S0002-93 78(18)30173-X/fulltext. Accessed 20 Dec 2019.

15. Poon LC, Rolnik DL, Tan MY, Delgado JL, Tsokaki T, Akolekar R, et al. ASPRE trial: incidence of preterm pre-eclampsia in patients fulfilling ACOG and NICE criteria according to risk by FMF algorithm. Ultrasound Obstet Gynecol Off J Int Soc Ultrasound Obstet Gynecol. 2018;51:738-42 https://obgyn. onlinelibrary.wiley.com/doi/full/10.1002/uog.19019. Accessed 20 Dec 2019.

16. Berhan $Y$, Berhan A. Should magnesium sulfate be administered to women with mild pre-eclampsia? A systematic review of published reports on eclampsia. J Obstet Gynaecol Res. 2015;41(6):831-42

17. Okonofua FE, Ogu RN, Fabamwo AO, Ujah IO, Chama CM, Archibong El, et al. Training health workers for magnesium sulfate use reduces case fatality from eclampsia: results from a multicenter trial. Acta Obstet Gynecol Scand. 2013;92(6):716-20 https://obgyn.onlinelibrary.wiley.com/doi/abs/1 0.1111/aogs.12135. Accessed 20 Dec 2019.
18. World Health Organization. Managing complications in pregnancy and childbirth: a guide for midwives and doctors. 2nd ed. Geneva: World Health Organization; 2017. https://apps.who.int/iris/bitstream/handle/10665/25576 0/9789241565493-eng.pdf. Accessed 20 Dec 2019.

19. Ronsmans C, Campbell O. Quantifying the fall in mortality associated with interventions related to hypertensive diseases of pregnancy. BMC Public Health. 2011;11(Suppl 3):S8 http://www.ncbi.n/m.nih.gov/pmc/articles/ PMC3231914/. Accessed 20 Dec 2019.

20. Long Q, Oladapo O, Leathersich S, Vogel J, Carroli G, Lumbiganon P, et al. Clinical practice patterns on the use of magnesium sulphate for treatment of pre-eclampsia and eclampsia: a multi-country survey. BJOG. 2017;124(12): 1883-90 https://www.ncbi.nlm.nih.gov/pmc/articles/PMC5697690/. Accessed 20 Dec 2019.

21. Lumala A, Sekweyama $P$, Abaasa A, Lwanga $H$, Byaruhanga R. Assessment of quality of care among in-patients with postpartum haemorrhage and severe pre-eclampsia at st. Francis hospital nsambya: a criteria-based audit. BMC Pregnancy Childbirth. 2017;17 https://www.ncbi.nlm.nih.gov/pmc/ articles/PMC5237263/. Accessed 20 Dec 2019.

22. Ali P, Butt $\mathrm{S}$, Hossain N. Criteria based audit in the management of eclampsia at a public sector tertiary care hospital in Karachi, Pakistan. Pregnancy Hypertens. 2018;11:111-4.

23. Bazant E, Rakotovao JP, Rasolofomanana JR, Tripathi V, Gomez P, Favero R, et al. Quality of care to prevent and treat postpartum hemorrhage and preeclampsia/eclampsia: an observational assessment in Madagascar's hospitals. Med Sante Trop. 2013:23(2):168-75.

24. Sheikh S, Qureshi RN, Khowaja AR, Salam R, Vidler M, Sawchuck D, et al. Health care provider knowledge and routine management of pre-eclampsia in Pakistan. Reprod Health. 2016;13(Suppl 2):104

25. Brenner S, De Allegri M, Gabrysch S, Chinkhumba J, Sarker M, Muula AS. The quality of clinical maternal and neonatal healthcare - a strategy for identifying 'routine care signal functions'. PLoS One. 2015;10(4) https://www ncbi.n/m.nih.gov/pmc/articles/PMC4398438/. Accessed 20 Dec 2019.

26. Zuleta-Tobón JJ, Pandales-Pérez H, Sánchez S, Vélez-Álvarez GA, VelásquezPenagos JA. Errors in the treatment of hypertensive disorders of pregnancy and their impact on maternal mortality. Int J Gynaecol Obstet Off Organ Int Fed Gynaecol Obstet. 2013;121(1):78-81.

27. Moodley J, Pattinson RC, Fawcus S, Schoon MG, Moran N, Shweni PM, et al. The confidential enquiry into maternal deaths in South Africa: a case study. BJOG Int J Obstet Gynaecol. 2014;121(Suppl 4):53-60.

28. Mahran A, Fares H, Elkhateeb R, Ibrahim M, Bahaa H, Sanad A, et al. Risk factors and outcome of patients with eclampsia at a tertiary hospital in Egypt. BMC Pregnancy Childbirth. 2017;17 https://www.ncbi.nlm.nih.gov/ pmc/articles/PMC5741945/. Accessed 20 Dec 2019.

29. WHO. Trends in maternal mortality 2000 to 2017: estimates by WHO, UNICEF, UNFPA, World Bank Group and the United Nations Population Division. Geneva: World Health Organization; 2019. http://www.who.int/reproductivehealth/ publications/maternal-mortality-2000-2017/en/ Accessed 15 July 2020.

30. Ministère du Plan et Suivi de la Mise en œuvre de la Révolution de la Modernité (MPSMRM), Ministère de la Santé Publique, ICF International. Enquête Démographique et de Santé en République Démocratique du Congo 2013-2014. Rockville: MPSMRM, MSP et ICF International; 2014. https://dhsprogram.com/pubs/pdf/FR300/FR300.pdf. Accessed 20 Dec 2019.

31. République Démocratique du Congo. Ministère de la Santé. Bulletin $N^{\circ} 1$ de la surveillance des décès maternels et riposte (SDMR). 2018. https://drc. unfpa.org/sites/default/files/pub-pdf/BULLETIN\%20SEMESTRIEL\%20N\%201\%2 OSDMR-RDCONGO.pdf Accessed 20 Dec 2019.

32. United Nations General Assembly. Transforming our world: the 2030 agenda for sustainable development. New York; 2015. http://www.un.org/ga/search/ view_doc.asp?symbol=A/RES/70/1\&Lang=E. Accessed 20 Dec 2019.

33. Nkamba DM, Ditekemena J, Wembodinga G, Bernard P, Tshefu A, Robert A. Proportion of pregnant women screened for hypertensive disorders in pregnancy and its associated factors within antenatal clinics of Kinshasa, Democratic Republic of Congo. BMC Pregnancy Childbirth. 2019;19:297 https:// www.ncbi.nlm.nih.gov/pmc/articles/PMC6694649/. Accessed 20 Dec 2019.

34. République Démocratique du Congo. Ministère de la Santé. Recueil des normes de la zone de sante. Kinshasa; 2006. https://www.who.int/hac/ techguidance/training/analysing_health_systems/5_normes_de_la_zone_ de_sante_06.pdf. Accessed 20 Dec 2019.

35. République Démocratique du Congo. Normes de la zone de sante relatives aux interventions intégrées de santé de la mère, du nouveau-né et de 
I'enfant en République Démocratique du Congo, vol. 2. Kinshasa: Soins obstétricaux d'urgence; 2012

36. World Health Organization. Service Availability and Readiness Assessment (SARA). An annual monitoring system for service delivery. Implementation guide: World Health Organization; 2013. https://apps.who.int/iris/bitstream/ handle/10665/112798/WHO_HIS_HSI_RME_2013_2_eng.pdf;jsessionid=A332 9C22896BF6EB61E2111C7256B4F8? sequence=1. Accessed 20 Dec 2019.

37. Ministère de la Santé Publique. Enquête sur la disponibilité et la capacité opérationnelle des services de santé en République Démocratique du Congo. Kinshasa: DSSP/DSNIS; 2014.

38. Jayanna K, Mony P, Ramesh BM, Thomas A, Gaikwad A, Mohan HL, et al. Assessment of facility readiness and provider preparedness for dealing with postpartum haemorrhage and pre-eclampsia/eclampsia in public and private health facilities of northern Karnataka, India: a cross-sectional study. BMC Pregnancy Childbirth. 2014;14:304 https://www.ncbi.nlm.nih.gov/pmc/ articles/PMC4161844/ Accessed 20 Dec 2019.

39. Ansari N, Manalai P, Maruf F, Currie S, Stekelenburg J, van Roosmalen J, et al. Quality of care in early detection and management of pre-eclampsia/ eclampsia in health facilities in Afghanistan. BMC Pregnancy Childbirth. 2019;19(1):36 https://www.ncbi.nlm.nih.gov/pmc/articles/PMC6339332/ Accessed 20 Dec 2019

40. Brown MA, Magee LA, Kenny LC, Karumanchi SA, McCarthy FP, Saito S, et al. The hypertensive disorders of pregnancy: ISSHP classification, diagnosis \& management recommendations for international practice. Pregnancy Hypertens. 2018;13:291-310.

41. Mondo TMN, Malengreau M, Kayembe Kalambayi P, Lapika Dimomfu B. Delays in seeking and getting care, in seriously ill women of childbearing age in Kinshasa. Rev Epidemiol Sante Publique. 2010;58(3):189-96.

42. Thaddeus S, Maine D. Too far to walk: maternal mortality in context. Soc Sci Med 1982. 1994;38(8):1091-110.

43. Sk MIK, Paswan B, Anand A, Mondal NA. Praying until death: revisiting three delays model to contextualize the socio-cultural factors associated with maternal deaths in a region with high prevalence of eclampsia in India. BMC Pregnancy Childbirth. 2019;19 https://www.ncbi.nlm.nih.gov/pmc/ articles/PMC6712765/. Accessed 20 Dec 2019.

44. Warren C, Ishaku S, Oginni AB, Adoyi G, Kirk KR, Dempsey A. Landscaping analysis for pre-eclampsia and eclampsia in Nigeria. Abuja: Population Council; 2015. p. 36. http://www.endingeclampsia.org/wp-content/ uploads/2017/04/EndingEclampsia-LandscapeReport-Nigeria.pdf Accessed 20 Dec 2019.

45. République Démocratique du Congo, Ministère de la Santé Publique. Normes et directives des interventions intégrées de santé de la mère, du nouveau-né et de l'enfant en République Démocratique du Congo. volume 1 soins: obstétricaux essentiels. Kinshasa; 2012.

46. République Démocratique du Congo, Ministère de laSanté Publique (MSP). Liste nationale des médicaments essentiels. Révision Juin 2014. Kinshasa: MSP; 2016.

47. Hanson C, Gabrysch S, Mbaruku G, Cox J, Mkumbo E, Manzi F, et al. Access to maternal health services: geographical inequalities, United Republic of Tanzania. Bull World Health Organ. 2017;95(12):810-20 https://www.ncbi. nlm.nih.gov/pmc/articles/PMC5710083/. Accessed 15 July 2020

48. Ooms Gl, Kibira D, Reed T, van den Ham HA, Mantel-Teeuwisse AK, Buckland-Merrett G. Access to sexual and reproductive health commodities in East and Southern Africa: a cross-country comparison of availability, affordability and stock-outs in Kenya, Tanzania, Uganda and Zambia. BMC Public Health. 2020;20 https://www.ncbi.nlm.nih.gov/pmc/articles/PMC73332 76/. Accessed 15 July 2020

49. Droti B, O'Neill KP, Mathai M, Dovlo DY, Robertson J. Poor availability of essential medicines for women and children threatens progress towards Sustainable Development Goal 3 in Africa. BMJ Glob Health. 2019;4(Suppl 9) https://www.ncbi.nlm.nih.gov/pmc/articles/PMC6797404/. Accessed 15 July 2020.

50. Basu S, Andrews J, Kishore S, Panjabi R, Stuckler D. Comparative performance of private and public healthcare systems in low- and middleincome countries: a systematic review. PLoS Med. 2012;9(6) https://www. ncbi.nlm.nih.gov/pmc/articles/PMC3378609/. Accessed 15 July 2020.

51. Vousden N, Lawley E, Seed PT, Gidiri MF, Goudar S, Sandall J, et al. Incidence of eclampsia and related complications across 10 low- and middle-resource geographical regions: secondary analysis of a cluster randomised controlled trial. PLoS Med. 2019;16(3) https:/www.ncbi.nlm.nih. gov/pmc/articles/PMC6440614/ Accessed 20 Dec 2019
52. Katageri G, Charantimath U, Joshi A, Vidler M, Ramadurg U, Sharma S, et al. Availability and use of magnesium sulphate at health care facilities in two selected districts of North Karnataka, India. Reprod Health. 2018;15(1):91 https://reproductive-health-journal.biomedcentral.com/articles/10.1186/s12 978-018-0531-6 Accessed 20 Dec 2019.

53. Williams A, Khan MA, Moniruzzaman M, Rahaman ST, Mannan II, de GraftJohnson J, et al. Management of preeclampsia, severe preeclampsia, and eclampsia at primary care facilities in Bangladesh. Glob Health Sci Pract. 2019;7(3):457-68 http://www.ghspjournal.org/content/early/2019/09/16/ GHSP-D-19-00124 Accessed 20 Dec 2019.

54. Mpunga Mukendi D, Chenge F, Mapatano MA, Criel B, Wembodinga G. Distribution and quality of emergency obstetric care service delivery in the Democratic Republic of the Congo: it is time to improve regulatory mechanisms. Reprod Health. 2019;16 https://www.ncbi.nlm.nih.gov/pmc/ articles/PMC6631736/ Accessed 15 July 2020.

55. Salomon A, Ishaku S, Kirk KR, Warren CE. Detecting and managing hypertensive disorders in pregnancy: a cross-sectional analysis of the quality of antenatal care in Nigeria. BMC Health Serv Res. 2019;19(1):411 https://www. ncbi.nlm.nih.gov/pmc/articles/pmid/31234838/. Accessed 20 Dec 2019.

56. Poon LC, Shennan A, Hyett JA, Kapur A, Hadar E, Divakar H, et al. The International Federation of Gynecology and Obstetrics (FIGO) initiative on pre-eclampsia: a pragmatic guide for first-trimester screening and prevention. Int J Gynecol Obstet. 2019;145(S1):1-33 https://obgyn. onlinelibrary.wiley.com/doi/full/10.1002/ijgo.12802. Accessed 20 Dec 2019.

57. e Holanda Moura SBM, Marques Lopes L, Murthi P, da Silva Costa F. Prevention of preeclampsia. J Pregnancy. 2012;2012 https://www.ncbi.nlm. nih.gov/pmc/articles/PMC3534321/. Accessed 20 Dec 2019.

58. Han A, Bujold E, Belizán M, Jaime J, Belizán J, Sharma S, et al. Preventing pre-eclampsia and its complications. In: The FIGO textbook of pregnancy hypertension. London: Global Library of Women's Medicine; 2016.

59. Althabe F, Chomba E, Tshefu AK, Banda E, Belizán M, Bergel E, et al. A multifaceted intervention to improve syphilis screening and treatment in pregnant women in Kinshasa, Democratic Republic of the Congo and in Lusaka, Zambia: a cluster randomised controlled trial. Lancet Glob Health. 2019;7(5):pe655-63 Disponible sur: https://www.thelancet.com/journals/ langlo/article/PIIS2214-109X(19)30075-0/fulltext. Accessed 20 Dec 2019.

60. Raney JH, Morgan MC, Christmas A, Sterling M, Spindler H, Ghosh R, et al. Simulation-enhanced nurse mentoring to improve preeclampsia and eclampsia care: an education intervention study in Bihar, India. BMC Pregnancy Childbirth. 2019;19(1):41 https://www.ncbi.nlm.nih.gov/ pubmed/30674286. Accessed 20 Dec 2019.

61. Nelissen E, Ersdal H, Mduma E, Evjen-Olsen B, Twisk J, Broerse J, et al. Clinical performance and patient outcome after simulation-based training in prevention and management of postpartum haemorrhage: an educational intervention study in a low-resource setting. BMC Pregnancy Childbirth 2017;17(1):301. doi: https://doi.org/10.1186/s12884-017-1481-7. Accessed 20 Dec 2019.

62. Casey SE, Mitchell KT, Amisi IM, Haliza MM, Aveledi B, Kalenga P, et al. Use of facility assessment data to improve reproductive health service delivery in the Democratic Republic of the Congo. Confl Health. 2009;3:12 https:// www.ncbi.nlm.nih.gov/pmc/articles/PMC2809040/. Accessed 20 Dec 2019.

\section{Publisher's Note}

Springer Nature remains neutral with regard to jurisdictional claims in published maps and institutional affiliations.

\section{Ready to submit your research? Choose BMC and benefit from:}

- fast, convenient online submission

- thorough peer review by experienced researchers in your field

- rapid publication on acceptance

- support for research data, including large and complex data types

- gold Open Access which fosters wider collaboration and increased citations

- maximum visibility for your research: over $100 \mathrm{M}$ website views per year

At BMC, research is always in progress.

Learn more biomedcentral.com/submissions 